\title{
Forecasting Waste Agricultural Plastics Generation in the Republic of Korea and its Policy Implications
}

\author{
Youngjae Chang ${ }^{1}$ \\ Geumsoo Kim²
}

'Professor, Division of Management Science, Inje University, South Korea

?Professor, Department of Global Commerce, Hoseo University, South Korea

Email:ngeumsoo@naver.com

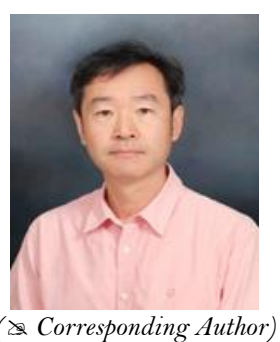

\begin{abstract}
The generation of waste plastics mulch is predicted to decline after 2019 and then stabilize at around 200,000 tons per year. This is within the current gross treatment capacity of private and public facilities. However, the Korean Waste Agricultural Plastics (WAP) management system is vulnerable to market uncertainty, which might lead to uncontrollable accumulation of untreated waste plastics as experienced in 2005. Shifting from the KECO (Korea Environment Corporation)led system to a more flexible market-oriented system is recommended.
\end{abstract}

Keywords: Waste agricultural plastics, Recycling, Waste management.

Citation | Youngjae Chang; Geumsoo Kim (2018). Forecasting Waste Agricultural Plastics Generation in the Republic of Korea and its Policy Implications. Agriculture and Food Sciences Research, $5(2): 68-72$.

History:

Received: 7 June 2018

Revised: 13 August 2018

Accepted: 18 September 2018

Published: 15 October 2018

Licensed: This work is licensed under a Creative Commons

Attribution 3.0 License $(\mathrm{cc}) \mathbf{E}$

Publisher:Asian Online Journal Publishing Group
Contribution/Acknowledgement: Both authors contributed to the conception and design of the study.

Funding: This study received no specific financial support.

Competing Interests: The authors declare that they have no conflict of interests.

Transparency: The authors confirm that the manuscript is an honest, accurate, and transparent account of the study was reported; that no vital features of the study have been omitted; and that any discrepancies from the study as planned have been explained.

Ethical: This study follows all ethical practices during writing.

\section{Contents}

1. Introduction 69

2. Korean WAP Management System

69

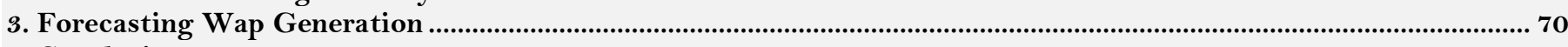

4. Conclusion 71

References.. 


\section{Introduction}

Modern farming takes advantage of a wide range of plastics and large amounts of WAP are inevitably generated. Vinyl-house horticulture and insulated rice seedbed preparation are practiced nationwide and, in 2015, approximately 320,000 tons of WAP was generated. This figure has remained almost the same over the last decade. The collection rate has stagnated at just under 60\%. Therefore, collection and proper treatment of WAP, including recycling, is a serious social concern in Korea.

In Korea, WAP are classified as municipal solid waste, the final treatment of which is the responsibility of the basic administrative districts (i.e., eup, myon, dong) ${ }^{1}$. Therefore, in principle, these districts have to collect and recycle or conduct final disposal (landfilling and incineration) of WAP. However, farmers do not have sufficient incentives to take waste plastics to private collectors or public collection points voluntarily and the basic administrative districts do not have the resources to deal with the waste fully. Waste vinyl-house plastic coverings are relatively clean and thus well-collected and almost recycled through market. However, the most prevalent type of waste plastics, mulching Low Density Polyethylene(LDPE) and High Density Polyethylene(HDPE), which accounted for $76 \%$ of the total 322,964 tons of waste generated in 2015, would create a serious problem if left intact in fields. Uncollected and improperly treated waste plastics are detrimental to the environment and also undermine agricultural land productivity.

For this reason, the KECO has established collection and treatment networks and subsidizes farmers and treatment firms in cooperation with local governments. In 2010, on average, 100 won per $\mathrm{kg}$ of collected waste came from subsidies of which 14 won was provided by the provincial government, 76 won by the city governments, and the remaining 10 won by the central government. However, this subsidization scheme has not been strong or flexible enough, resulting in insufficient and stagnated collection rates. As urbanization has advanced, now in farms only the old people are left. This trend is making it more expensive to bring waste plastics to collection points, but the level of subsidies has remained almost the same for a long time. On the treatment side, there has sometimes been overcapacity and insufficient capacity at other times. This disequilibrium in market may be resolved by price adjustment. However, this takes time and there are highly likely to be negative impacts such as a backlog of untreated waste plastics. To ease this fluctuation in demand and supply KECO operates treatment companies and subsidized private treatment companies. The focus of this paper is not on the design of this system but only on the provision of materials to aid discussion by estimating and predicting WAP generation and collection.

The paper is organized as follows. In the next section, we provide an overview of the Korean WAP management system, including time trends of WAP generation and collection, WAP-related materials flow, and so on. In section 3, we forecast WAP generation and collection for the next 5 years and compare this with the current treatment capacity. We then discuss the policy implications of our empirical results. Finally, Section 4 contains some concluding remarks.

\section{Korean WAP Management System}

\subsection{Legal Position of WAP in the Korean Waste Management System}

WAP is municipal solid waste and the collection and final treatment of it is the responsibility of the basic administrative districts in Korea. Therefore, farmers here do not have as strong an incentive for collecting and properly treating as farmers in Japan and Taiwan, who are responsible for the proper final treatment and thus almost all WAP is collected and treated via proper channels [1,2].

\subsection{Materials Flow in WAP Management and KECO}

As shown Table 1 the total amount of generated WAP has remained around 320,000 tons per year for the last decade. Mulching LDPE is the most prevalent type of waste (approximately 40\%), followed by HDPE (35\%) and vinyl-house LDPE (20\%).

Table-1. WAP Generation, Collection, and Treatment in Korea

\begin{tabular}{l|c|c|c|c|c} 
Unit: tons & \multicolumn{1}{l}{} \\
\hline Year & Generation & Collection & Collection rate (\%) & Treatment & Untreated Inventory \\
\hline 2009 & 310,009 & 189,238 & 61.04 & 236,259 & 72,973 \\
\hline 2010 & 324,101 & 176,849 & 54.57 & 208,377 & 41,444 \\
\hline 2011 & 331,490 & 181,609 & 54.79 & 185,424 & 37,628 \\
\hline 2012 & 337,877 & 178,130 & 52.72 & 180,950 & 34,809 \\
\hline 2013 & 332,575 & 189,306 & 56.92 & 174,181 & 49,934 \\
\hline 2014 & 329,239 & 188,279 & 57.19 & 193,065 & 45,168 \\
\hline 2015 & 322,964 & 186,965 & 57.89 & 211,143 & 21,141 \\
\hline Sor &
\end{tabular}

Farmers are advised to bring any generated WAP to community collection points. At this stage local governments subsidize farmers to increase their collection rate, combining the subsidies from the KECO (or central government) and the provincial government. Designated private collectors then bring the collected WAP to KECO-operated storage facilities. (see Figure 1). The collection rate has not exceeded $60 \%$ for the last decade. What has contributed the most to the low collection rate was House LDPE (see Table 2), but this one was almost recycled voluntarily through market. A total of 72,000 tons of mulching LDPE, HDPE, PVC and other waste plastics went uncollected, which is a real problem. 
Unit: tons per year, \%

Table-2. Collection Rate by Type (2015)

\begin{tabular}{l|c|c|c}
\hline & Generation(a) & Collection(b) & Collection rate $(\mathbf{b} / \mathbf{a}) * 100)$ \\
\hline House LDPE & 69,414 & 4,964 & 7.15 \\
\hline Mulching LDPE & 128,241 & 88,275 & 68.84 \\
\hline HDPE & 118,715 & 92,064 & 77.55 \\
\hline PVC and others & 6,594 & 4,914 & 74.52 \\
\hline Total & 322,964 & 186,965 & 57.89 \\
\hline
\end{tabular}

KECO has two options for the treatment of collected WAP: KECO itself treats or gets it done by private firms. As of 2016, KECO operates seven treatment facilities with a treatment capacity of 80,000 tons per year. In 2015, just over 100 thousands tons should be left for private firms. Six of treatment firms have the capacity to process 6,000-8,000 tons each per year. KECO auctions off some part of the remaining WAP to private firms and for the other part of the remaining WAP, KECO subsidizes private firms to treat. The treatment subsidy was introduced in 2005 when the volume of untreated WAP became a serious social concern. The subsidy was at its highest level in 2008 but has been declining since then.

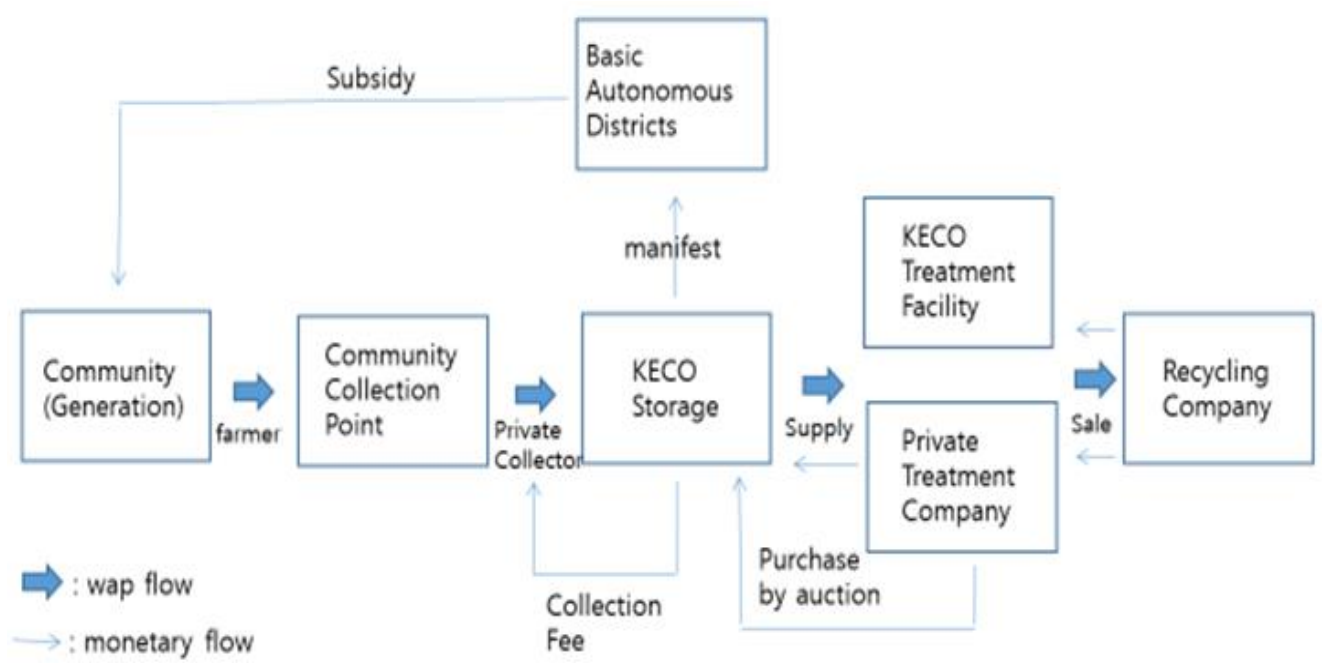

Figure-1. Flow diagram of WAP generation, collection, and treatment

Source: KECO internal data

\section{Forecasting Wap Generation}

\subsection{Methodology}

Forecasting is a two-state process. First, we attempt to identify the determinants of WAP generation $(M P E)$ through a regression analysis. Specifically, WAP generation is regressed on potential determinants such as paddy size (paddy), field size (field) and vinyl-house farming (House) as follows

$$
\text { MPE }=\beta_{0}+\beta_{1} \text { paddy }+\beta_{2} \text { field }+\beta_{3} \text { House }+\varepsilon
$$

Based on this estimation, we then forecast the future MPE. To do this, we need to estimate the future values of explanatory variables: we regress each of the explanatory variables on the respective previous values and time. We use the estimated value of one coefficient as its future value if it is statistically significant. If there is no statistical significance, we will average the previous 5 years' values to use as future values for each variable over 5 years.

\subsection{Data}

We use panel data covering nine regions across 12 years (2004 through 2015) ${ }^{2}$. As our dependent variable, we use only waste mulching plastics generation, which accounts for approximately $80 \%$ of the total, because the remainder, vinyl house coverings, is almost recycled voluntarily through the market. Table 3 provides summary statistics for our data.

Table-3. Summary Statistics

\begin{tabular}{l|c|c|c|c}
\hline & MPE & Paddy & Field & House \\
\hline Mean & $26,289.56$ & $106,379.23$ & $4,439.76$ & $80,904.06$ \\
\hline Stand. dev. & $12,146.60$ & $61,947.29$ & $4,729.77$ & $27,252.56$ \\
\hline Min. & $1,319.00$ & 18.00 & 0.00 & $52,100.00$ \\
\hline Max. & $59,634.00$ & $219,337.00$ & $18,287.00$ & $152,095.00$ \\
\hline
\end{tabular}

Note: MPE, paddy, field, and House stands for mulching plastics generation, size of paddy field, size of dry field, and size of

vinyl house, respectively. MPE is measured in tons and the other variables are measured in hactares.

Source: KECO internal data and the Korea Statistical Information Service(kosis.kr).

${ }^{2}$ As of 2018 , there are 16 so-called wide autonomous administrative units in Korea. However, due to the availability of data, we have merged these units into nine regions. For example, Seoul and its surrounding Kyunggi Province were merged into an area referred to as the Captial area. 


\subsection{Empirical Results}

We first checked the poolability of the time-series and cross-sectional data. Based on an F-statistic (0.42652) we could reject the null hypothesis that the coefficients are not stable at the $5 \%$ level. We then checked for autocorrelation in error terms using the Breusch-Godfrey/ Wooldridge test, which has detected the presence of autocorrelation. We have added the lag term for dependent variable to set our final regression model as follows:

$$
\text { MPE }=\beta_{0}+\beta_{1} \text { paddy }+\beta_{2} \text { field }+\beta_{3} \text { House }+\beta_{4} \operatorname{lag}(\mathrm{MPE})+\varepsilon
$$

We have found no autocorrelation in error terms after testing this new model using the Breusch-Godfrey/ Wooldridge test (chi-square statistic $=2.1548$ ). In addition, the Honda Test showed no individual effect (standard normal statistic $=0.024989$ ), but a time effect (standard normal statistic $=4.6167)$. Finally by using the Hausman test we selected a random effects model (chi-square statistic=5.6698) [3, 4].

Table 4 presents the results of regression analysis. House (size of vinyl house farming) and lag(MPE) are significant at the $5 \%$ and $1 \%$ level, respectively. The effect of lag(MPE) is statistically significant and is strong. Almost 67 percent of WAP generated in the last year is again generated any of this year in inertia. Notice that the effect of field (size of dry field) is almost the same as that of House (size of vinyl house farming), but it is not statistically significant.

Table-4. Results of Regression Analysis

\begin{tabular}{l|c|c|c|c}
\hline & Coefficient & Standard error & t-value & P-value \\
\hline Intercept & 574.9600 & 1901.1000 & 0.3024 & 0.7630 \\
\hline Paddy & 0.0189 & 0.0116 & 1.6276 & 0.1070 \\
\hline Field & 0.0893 & 0.1403 & 0.6361 & 0.5263 \\
\hline House & 0.0737 & 0.0302 & 2.4409 & $0.0165 *$ \\
\hline Lag(MPE) & 0.6715 & 0.0749 & 8.9676 & $0.0000^{* * *}$ \\
\hline
\end{tabular}

We now turn to predicting the future values of explanatory variables. We then insert them into Equation (2) to obtain the future values of MPE. Table 5 shows a summary of the future values of explanatory variables obtained using the aforementioned method.

Table-5. Future Values of Explanatory Variables

\begin{tabular}{l|c|c|c}
\hline Year & Paddy & Field & House \\
\hline 2016 & $998,953.6$ & $273,912.4$ & $989,065.2$ \\
\hline 2017 & $992,768.4$ & $274,119.1$ & $973,989.8$ \\
\hline 2018 & $985,095.7$ & $274,911.6$ & $984,324.6$ \\
\hline 2019 & $940,259.2$ & $258,131.9$ & $992,162.6$ \\
\hline 2020 & $914,167.4$ & $234,499.8$ & $968,638.2$ \\
\hline
\end{tabular}

The 95\% confidence interval for the predicted values of MPE is summarized in Table 6.

Table-6. 95\% Confidence Interval for the Prediction of MPE

\begin{tabular}{l|c|c|c}
\hline Year & Lower Bound & Point Estimate & Upper Bound \\
\hline 2016 & $221,466.6$ & $247,363.4$ & $273,260.2$ \\
\hline 2017 & $224,616.4$ & $247,827.1$ & $271,037.8$ \\
\hline 2018 & $226,404.7$ & $248,955.6$ & $271,506.6$ \\
\hline 2019 & $190,964.2$ & $232,544.9$ & $274,125.6$ \\
\hline 2020 & $174,274.4$ & $209,293.8$ & $244,313.2$ \\
\hline
\end{tabular}

As shown in Table 6, the generation of MPE is predicted to decline after 2019. It is also predicted to stabilize at around 200,000 tons per year after that. Although there is a little increase in the MPE collection rate, for example $80 \%$, there would be no repeat of the huge accumulation of WAP that occurred on 2005 because the present treatment capacity (approximately, private 50 thousand and public 80 thousand annually) would suffice. However, due to the uncertainty in the recycled products market (for example, China's recent suspension of recycled vinyl imports and fluctuations in petroleum markets) private WAP recycling firms may go bankrupt, causing a supply shortage for treatment services, which occurred in 2005.

\section{Conclusion}

The amount of WAP collected by KECO is predicted to stabilize at around 160,000 tons per year. Given the current treatment capacity, this would not lead to issues if the amount of untreated WAP significantly increased, as it did in 2005. However, this KECO-led system is vulnerable to various market uncertainties regarding recycled products and petroleum markets.

Unlike Korea, Japan and Taiwan define WAP as industrial waste. Therefore, farmers in these countries are responsible for the proper treatment of WAP. In both countries the central government does not play such active a role as it does in Korea. Collection and treatment occur in response to market mechanisms [5-7]. In light of the situation in these countries, Korea also needs to strengthen the legal responsibility of producers and consumers (farmers) of agricultural plastics to ensure proper WAP management. Specifically, we can consider the alternatives that by putting agricultural plastics into EPR(Extended Producer's Responsibility) items, producers are made 
responsible for collecting and treating WAP or that by reclassifying WAP into industrial waste farmers are made responsible for proper treatment [8].

We do not exclude the role of governments in WAP management. Governments may adopt the role of facilitating the smooth operation of markets. Taiwanese government compensates farmers for sorting and bringing waste plastic containers to treatment firms, but not for general WAP. Japanese government also compensates farmers for bringing waste plastics to collection points. In addition, it also operates a minimum level of public treatment facilities as a buffer for market uncertainty $[6,7]$.

\section{References}

[1] E. Hosoda, Waste policies and related legislation in Japan. Ch.1 In The economics of waste management in East Asia- Ed. by M. Yamamoto and E. Hosoda. NY, USA: Routledge, 2016.

[2] S. C. Lee, An introduction to Taiwan's waste management and recycling policy. Ch.6 In the economics of waste management in East Asia- ed. by M. Tamamoto and E. Hosoda. NY, USA: Routledge, 2016.

B. H. Baltagi, Econometric analysis of panel data, 2nd ed. UK: John Wiley \& Sons, 2001.

W. H. Greene, Econometric analysis. NY, USA: MacMillan, 1990.

H. Takeya, "Collection, disposal and exchange of waste agricultural plastics in Japan, the Republic of Korea and China," Tech Monitor, pp. 50-55, 2009.

[6] NIER(National Institute of Environmental Research), "Japanese resource circulation institutions and status of $3 \mathrm{R}$ reference book. NIER, ROK, 2015.(in Korean)," 2015.

[7] TEPA (Taiwanese Environmental Protection Administration), Retrieved: www.epa.gov.tw, 2017.

[8] R. Porter, The economics of waste. Washington DC, USA: Resources for the Future, 2002. 